\title{
Acceptability of Micro-Insurance Scheme Among Teachers in Public Secondary Schools in Lagos state, Nigeria.
}

\author{
Bamgbose, O.S. \& Adekanbi, 0. \\ Department of Insurance \\ Lagos State Polytechnic \\ Ikorodu, Lagos. Nigeria \\ Email: sodiq.bamgbose1976@gmail.com; oluyemiadekanmbi@gmail.com \\ Phone: +2349070459964; +2349018025579, +08027599644
}

\begin{abstract}
Low income earning workers such as the teachers in the public secondary schools, are faced with varying categories of financial risk which cannot e alleviated without the help of some other social arrangement such as micro-insurance schemes. However, these scheme has not been well accepted among the teachers. The study however, looked at the reasons for the low acceptability. A stratified simple random sampling technique was used to collect data from a sample of 384 secondary school teachers in Lagos state, using regression analysis techniques. Adequate knowledge and well structured products designs of the micro-insurance products does not influence the acceptability of the products among the teachers. The study result however, shows that not making the products compulsory is the major factor that influence the acceptability among the teachers.
\end{abstract}

Keywords: micro-insurance, public secondary schools, low income earners, financial risk, adequate knowledge, product design

Proceedings Reference Format

Bamgbose, O.S. \& Adekanbi, O. (2021): Acceptability of Micro-Insurance Scheme Among Teachers in Public Secondary Schools in Lagos state, Nigeria. Proceedings of the 27th iSTEAMS Multidisciplinary Innovations \& Technology Transfer (MINTT) Conference. Academic City University College, Accra, Ghana. June, 2021. Pp 362-372 www.isteams.net/ghana2021.

DOI - https://doi.org/ 10.22624/AIMS/iSTEAMS-2021/N27P32

\section{INTRODUCTION}

It is a common knowledge that workers both in the public and private sector spends their wages on critical needs such as rent, school fees, food, transportation, recharge cards and healthcare (moller,2004). They are also predominantly expose to economic risk, natural risk, health risk, life cycle risks, policy based and institutional risks, social and political risk (Geneva, ILO-STEP). Various government including Nigeria, historically have been able to introduce some forms of ad-hoc interventions programmes such as mortgage rent reduction, reduction in taxes, cancellation or postponement of loan payment and other form of direct subsidies (Townsend, 1994). Majority of these measures are privileges and not "right" in most developing countries including Nigeria (Sigma, 2005; UNDP 2003). 


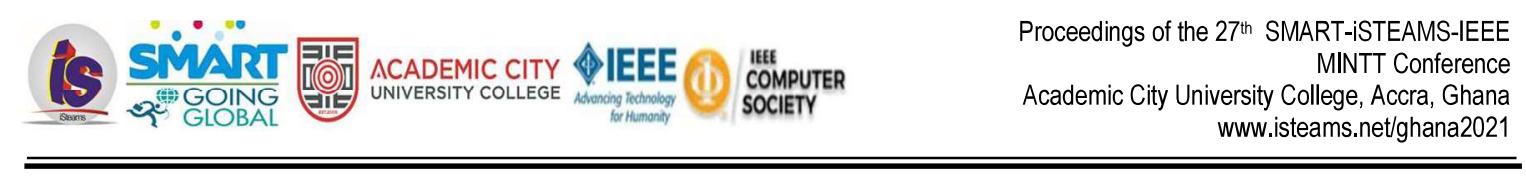

Therefore, most low income workers cannot take these palliatives into consideration when making day to day economic decisions, insurance in the form of micro insurance takaful, health micro insurance and transportation insurance are therefore needed to fill in these gap between government and the less privileged low income earning workers such as teachers in the public secondary schools (Osoka, 1992).

\subsection{Scope of the study}

The research was a cross sectional study that is based on the urban population in Nigeria, with the specific target population of the teachers from grade level 5-15 in the public secondary school. The choice was based on the assumption that the target population will have adequate knowledge of micro-insurance schemes. It was carried out in the Alimosho, Ajeromi Ifelodun and the Ikorodu local government areas of Lagos state.

\subsection{Research Objectives;}

i. To ascertain risk facing the various grade level teachers in the public sector.

ii. To ascertain if there are adequate micro- insurance products coverage for the teachers in the public service.

iii. To ascertain the level of awareness regarding micro- insurance availability among the teachers in the public secondary schools.

iv. To ascertain what factors influences the acceptability of micro-insurance schemes amongst the teachers in the public secondary schools.

\subsection{Research Questions;}

i. Are the micro-insurance products well designed to appeal to the low income earning teachers in the public sector?

ii. Will micro insurance help improve the living standard of the low income earning teachers in the public sector?

iii. Is there adequate knowledge of micro-insurance products amongst the teacher?

\subsection{Statement of the Problem}

In most developing countries including Nigeria, communities and households are faced with multiple risks, this includes workers both in the formal and informal sector. Adverse events of risk often have financial consequences on their level of income and consumption, for example illness and injury have evident cost for prevention, care and cure, and opportunity cost (loss of income while ill) (Castel,2003). Households are often coerced to make choices such as depleting productive assets, reducing food intake, or withdrawing children from school, which tends to jeopardize their economics and human developmental prospect, which leaves them stuck in poverty trap (Chatterjee \& Ranson, 2006). micro-insurance as a mechanism that is intended in providing coverage against financial consequences resulting from the uncertain events of risk (Reynaud, 2005). the scheme is built to cover some categories of people that are excluded from statutory social security, mostly in the formal and informal economy (Khahly et al, 2008).

Despite the aforementioned benefits of micro-insurance, the acceptability of the schemes amongst teachers in the public secondary school is considerably low. Therefore, in order to prevent workers and their household from being permanently exposed to the financial consequences of the aforementioned adverse risk. The study therefore formulated the following hypothesis: Ho1- lack of adequate knowledge amongst teachers in the public secondary schools is not the cause of their non- acceptability of micro-insurance schemes. 


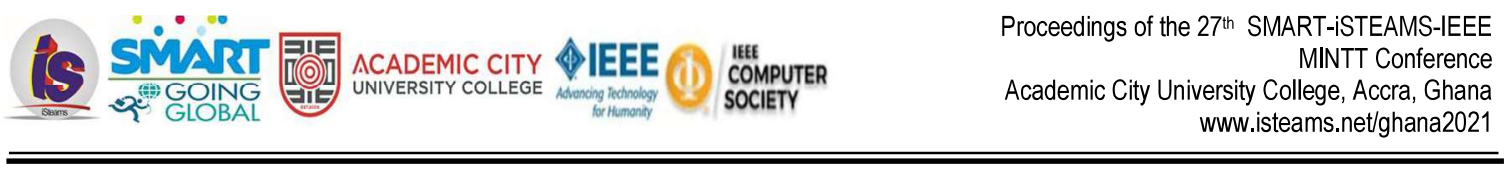

Ho2- micro-insurance products not being well designed to appeal to the low income earning teachers in the public secondary school affects the acceptability of the scheme.

Ho3- Lack of statutory compulsion of micro-insurance schemes does not affect the acceptability amongst the teachers in the public secondary schools.

\subsection{Methodology}

This study used stratified and simple random sampling techniques. This technique was justified for use because it is based on scientific rules of probability and it also ensures adequate representation of the study group. Statistical formula from (krejcie \& Morgan 1970) was used to determine the size of 384 from the population of 3,500 . A well-structured questionnaire was used to collect necessary data from the respondents. The data obtained were compiled and analysed using linear regression

\section{LITERATURE REVIEW}

\subsection{Models relevant to the study}

In $2003 \mathrm{ICICI}$ Lombard launched an ambitious scheme targeted at low- income farmers in Andbra Pradesh, India, which is sold through Basix and MFI. To date 200,000 low-income earning farmers in 130 locations have been covered. The scheme insures against deficit, excess and unseasonal rainfall, high relative humidity, excessively high and low temperatures, prolonged dry spell, as well as a combination of these risks. In the late 1990s, Grameen kalyan, in Bangladesh, launched micro health insurance scheme, which presently covers half a million people. Its premium is about two US dollars per year and it operates about 33 clinics in ten districts in Bangladesh. Grameem kalyam plays both the roles of insurer and of direct service provider. It uses the strategy of servicing the community at large and of charging higher rates for the less poor.

Yasiru, in sri-lanka, started off by insuring over 9,000 people. It offers a mixed bag of life accident and funeral insurance and its premium range is USD 1.20-18.00, per year, though it first started as an in -house insurance service in a federation of NGOs called ACCDC, today it has active partner with around 60,000 members.

\subsection{Theories Relevant to the Study}

This section of the literature review summaries critical theories used to conceptualise the factors influencing the acceptability of micro-insurance schemes among the teachers in the public secondary schools. The theories include the Decision Making Theory and the Theory of Reasoned Action

\subsection{Decision Making Theory}

The theory was propounded by Levi (1974). This theory encompasses a body of knowledge and related analytical technique of different degrees of helping a decision maker choose among a set of alternatives in light of their possible consequences. Mckinsey; (2009) argued that the decision making process of a consumer can be depicted in funnel shape. where consumers systematically narrow the initial-consideration set as they weigh options, make decisions, and buy products. 
A consumer goes through several stages before purchasing a product or service.

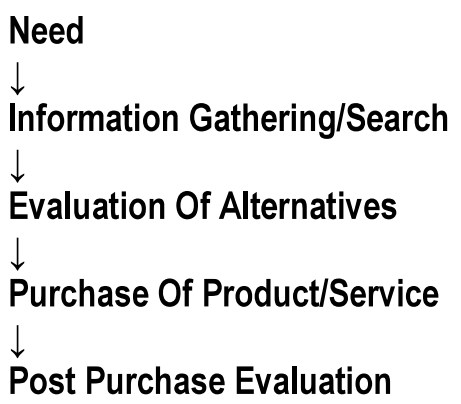

Step 1 - Need is the most important factor which leads to buying of products and services. Need in fact is the catalyst which triggers the buying decision of individuals. An individual who buys cold drink or a bottle of mineral water identifies his/her need as thirst. However, in such cases steps such as information search and evaluation of alternatives are generally missing. These two steps are important when an individual purchases expensive products/services such as laptop, cars, mobile phones and so on.

Step 2 - When an individual recognizes his need for a particular product/service he tries to gather as much information as he can. An individual can acquire information through any of the following sources:

- Personal Sources - He might discuss his need with his friends, family members, co-workers and other acquaintances.

- Commercial sources - Advertisements, sales people (in Tim's case it was the store manager), Packaging of a particular product in many cases prompt individuals to buy the same, Displays (Props, Mannequins etc.)

- Public sources - Newspaper, Radio, Magazine

- Experiential sources - Individual's own experience, prior handling of a particular product (Tim would definitely purchase a Dell laptop again if he had already used one)

Step 3 - The next step is to evaluate the various alternatives available in the market. An individual after gathering relevant information tries to choose the best option available as per his need, taste and pocket.

Step 4 - After going through all the above stages, customer finally purchases the product.

Step 5 - The purchase of the product is followed by post purchase evaluation. Post purchase evaluation refers to a customer's analysis whether the product was useful to him or not, whether the product fulfilled his need or not 
(2)

Consumers add or subtract

brands as they evaluate what

they want.

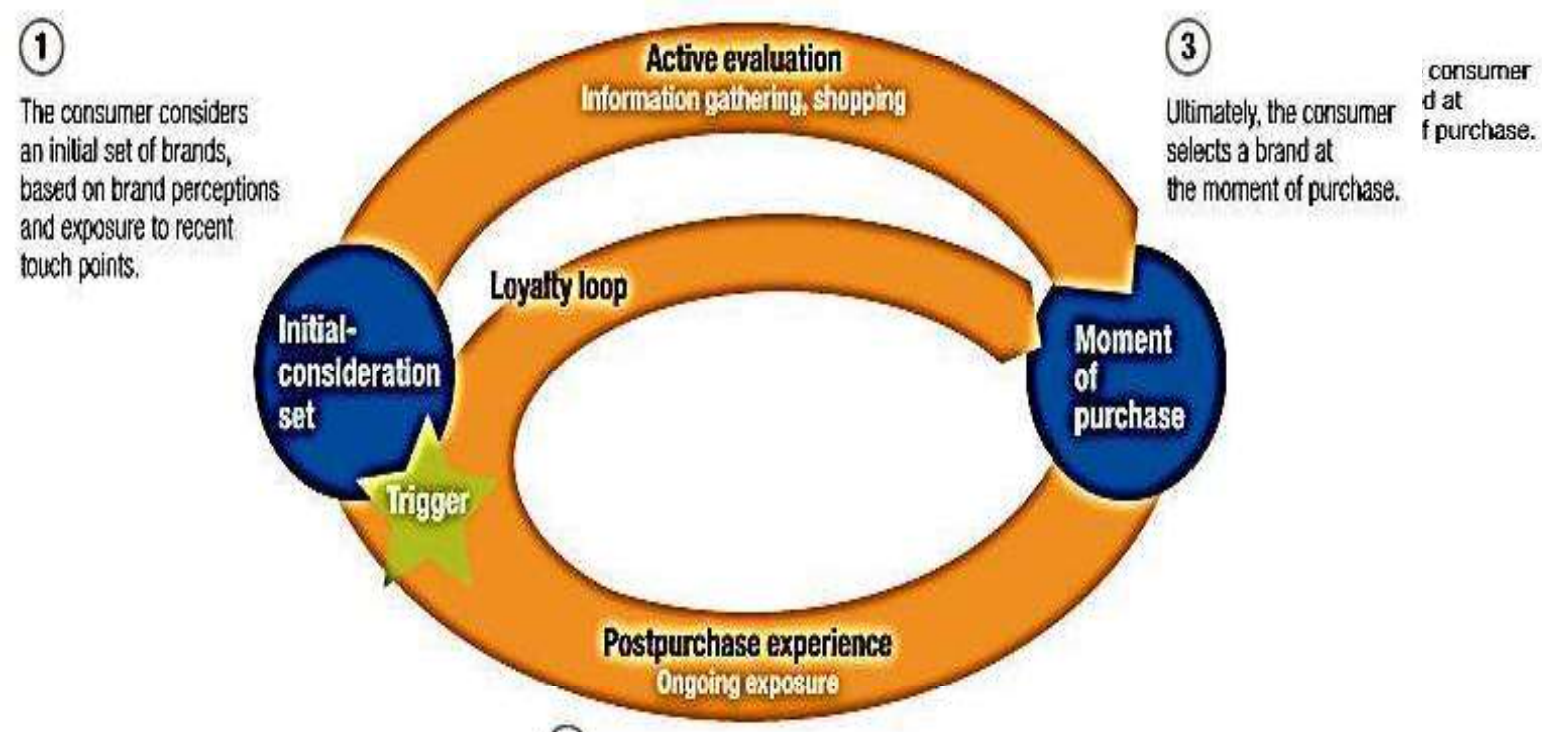

(4)

After purchasing a product or service,

the consumer bullds expectations

based on experience to inform the next

decision journey.

Figure 2.1: The Modified Consumer Decision Making Process

Source: McKinsey, (2010)

\subsection{Theory of Reasoned Action}

Nennaaton \& Ezema (2016) stated that to understand better the pattern of customer patronage is through several theories. One of which is most significant is the "Theory of Reasoned Action" (TAR), developed by Fisheim \& Ajzem (1980). The theory asserts that "people have a high degree of volitional control and make reasoned choices among alternatives" (Ajzem \& Fisheim,1975).

The theory explains that the functional intention is predicted to these two factors. The theory relates to the current research as it set the pace for customer patronage which affects sales performance as a result of social interaction and engagement. In essence, the main theories that underpin this research study includes Decision Making Theory and the Theory of Reasoned Action. 


\section{WHAT IS MICRO-INSURANCE}

Micro-insurance scheme is an insurance that is basically developed for low income populations, they are built to cover people excluded from statutory social security, notably the workers in the Informal economy and their families. Micro-Insurance schemes are most often initiated and operated by organisations or civil society such as trade unions, NGOs, Micro- Finance Institutions (MFIs), Cooperatives, Community based organizations, Mutual Health Organizations (NAICOM ANNUAL REPORTS,2013). In the Nigeria economy, the operation of micro-insurance business was legally recognized to be enforced from $1^{\text {st }}$ January, 2014. In line with the national insurance commission (NAICOM) guidelines. 150.000,000, 200,000,000 and 350,000,000 are stipulated as the minimum capitalisation requirements for life, general and composite micro-insurance companies respectively. Micro-insurance scheme products are designed to be appropriate for the low income market in relation to cost, coverage, terms and delivery mechanism (Townsend, 1994).

\subsection{Forms and Coverage of Micro-Insurance Products}

\section{Life Micro-Insurance Retirement Savings Plans}

Brown, w; Churchill, c (2006) describe life micro-insurance retirement savings plan as a product that provides coverage against financial consequences upon the death of a bread winner or of old age. Life micro-insurance products are usually classified into two based on the period of compensation payment (Siegel, p.v; Alwamg, j; Camagarajih, s.r,2001). Under the first category, the compensation is paid upon the death of the insured person (worker). Example includes term life micro-insurance and credit-life micro-insurance. The second category, pays compensation after a predetermined period (usually after a minimum period of 5 years) either on the death of the policy holder or while the insured person is still alive. Examples includes endowment and annuities.

\section{Health Micro-Insurance (Hospitalisation, Primary Health Care, Maternity)}

III-health and maternity usually comes along with financial consequences (Atim, Chrisiet.et.al,1998). These financial consequences are usually covered against under the health micro-insurance scheme. the financial consequences include; the direct medical costs for prevention, care and cure such as fees for consultations, laboratory tests, medicines, hospitalisation, delivery. The direct non -medical costs such as costs for transportation, food in case of hospitalisation as ill-health and maternity usually causes a loss of productive time for both patients and caretaker (Baeza, Cristia, et al.2002).

\section{Disability Micro-Insurance Scheme}

Disability micro-insurance provides coverage against the financial consequences of invalidity, whether temporary or permanent (Dercom \& Stetar, 2005). Disability is temporary when the physical loss is reversible and last for a limited period of time(Reynaud,2005). The scheme covers variety of disability events that needs to be precisely defined in advance. The pre-defined financial compensation can be proportional to the severity of the disability. Disability micro-insurance is often appreciated by micro-insurance institutions in order to secure the reimbursement of the loans (Banerjee, Upala Devi, (2003a). It is called "credit disability micro-insurance" which covers the repayment of the outstanding balance of the loan in case of disability of the borrower (Brown w, Churchill, C. 1999/2000a). 


\section{Property Micro-Insurance (Assets, Livestock's and Housing)}

Property micro-insurance provides coverage against the financial consequence of the damage or loss of personal assets, work premises and tools (Cohen, Monique, seestad, Jennifer, 1999). the insured person is usually the owner of the assets and /or the tools. The financial compensation is assessed once the adverse event has occurred.

\section{Savings and Emergency Credit Micro-Insurance Scheme}

This program is provided to members of the Micro-Insurance schemes in order to give protection against risk which are not covered by micro-insurance scheme (Reynaud,2005b). Savings and Emergency credit programs are particularly appropriate for minor risks that entails moderate expense and have a high probability of occurrence (Banerjee, Upala Devi,2003b). It is also used to provide supplementary protection when adverse events resulting in financial consequence occurs (Brown w, Churchill 2000b)

\section{RESULTS AND DISCUSSIONS}

\section{Hypothesis 1}

Lack of adequate knowledge amongst teachers in the public secondary schools is not the cause of their nonacceptability of micro-insurance schemes.

Table 1: Regression analysis showing the influence of lack of adequate knowledge of teacher in the public secondary school towards the acceptability of micro-insurance schemes.

\begin{tabular}{|c|c|c|c|c|c|}
\hline & \multicolumn{2}{|c|}{$\begin{array}{l}\text { Unstandardized } \\
\text { Coefficients }\end{array}$} & \multicolumn{3}{|c|}{$\begin{array}{c}\text { standardized } \\
\text { coefficients }\end{array}$} \\
\hline Model & $\mathrm{B}$ & Std. Error & Beta & $t$ & Sig \\
\hline (constant) & 3.844 & 1.411 & & 2.725 & .007 \\
\hline Adequate Knowledge & 0.083 & 0.131 & 0.045 & 0.635 & 0.526 \\
\hline
\end{tabular}

Multiple R -0.045 , Multiple $R^{2}-0.002$, Adjusted $R^{2}=0.003, F 1.196-0.403$ $p>0.05$

Table 1 reveals that lack of adequate knowledge have little or no influence on the acceptability of microinsurance schemes amongst the teachers in the public secondary schools. ( $F 1.196-0.403 . p>0.05)$. the null hypothesis is not rejected. This implies that there is adequate knowledge of micro- insurance amongst the teachers in the public secondary schools, hence it does not influence the acceptability of micro-insurance among the teachers. The value of the coefficient determination $\left(R^{2}-0.002\right)$ indicates that all the predictor variable only accounted for less than $1 \%\left(R^{2} \times 100\right)$ of the observed variance of the acceptability variance. The calculated $\mathrm{F}$ - ratio $(0.403)$ is not significant at 0.05 level of significance. This implies that the predictor variable does not provide a significant explanation for the acceptability of micro-insurance schemes amongst the teachers. 


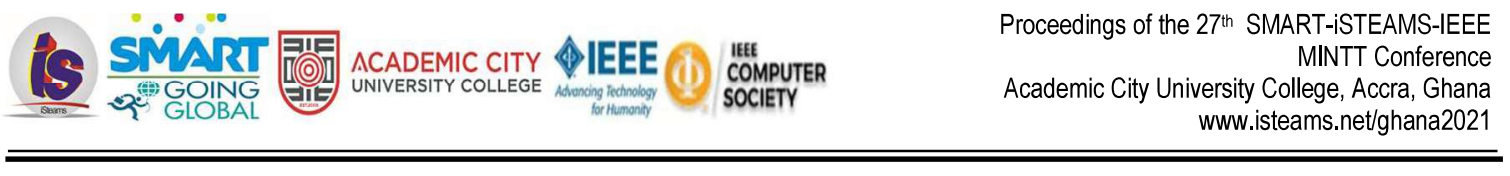

Hypothesis 2

Micro-insurance products not being well designed to appeal to the low income earning teachers in the public secondary school does not affects the acceptability of the scheme.

Table 2: Regression analysis showing the influence of design of product of the acceptability of micro-insurance amongst the teachers in the public secondary school.

\begin{tabular}{|c|c|c|c|c|c|}
\hline & \multicolumn{2}{|c|}{$\begin{array}{l}\text { Unstandardized } \\
\text { Coefficients }\end{array}$} & \multicolumn{3}{|c|}{$\begin{array}{r}\text { standardized } \\
\text { Coefficients }\end{array}$} \\
\hline Model & $B$ & Std. Error & Beta & $\mathrm{t}$ & Sig \\
\hline 1 constant & 2.239 & 0.519 & & 4.316 & .000 \\
\hline Products Designs & 0.047 & 0.048 & 0.070 & 0.978 & 0.329 \\
\hline
\end{tabular}

The results in table 2 above, shows that micro-insurance product design have little or no influence on the acceptability of micro-insurance schemes among teachers in the public secondary schools (F 1.196 -0.957. $p>0.05)$. the null hypothesis is not rejected. The table reveals that the relationship between the acceptability and the design of micro-insurance products is very low, negative and statistically insignificant at 0.05 level ( $\beta$ $0.070, p>0.05)$. This implies that the design of micro-insurance products does not influence the acceptability of micro-insurance schemes amongst the teachers and vice versa. That is the acceptability of micro-insurance scheme is not influence by the design of the products. The value of the coefficient determination $\left(R^{2}-0.005\right)$ indicates that the predictor variable only explained less than $1 \%\left(R^{2} \times 100\right)$ of the observed variance in the acceptability of micro-insurance amongst teachers in the public secondary schools in Lagos. The calculated Fratio $(0.957)$ is not significant at 0.05 level of significance. This implies that the predictor variable does not provide a significant explanation for the variation in the acceptability of micro-insurance products amongst the teachers in the public secondary schools.

\section{Hypothesis 3}

Lack of statutory compulsion of micro-insurance schemes does not affect the acceptability of Micro-Insurance Schemes amongst the teachers in the public secondary schools.

Table 3: Regression analysis showing the influence of compulsory statutory regulation on the acceptability of Micro-Insurance Schemes amongst the teachers in the public secondary school in Lagos.
Unstandardized
standardized
Coefficients
Coefficients

\begin{tabular}{|c|c|c|c|c|c|}
\hline Model & B & Std. Error & Beta & $t$ & Sig \\
\hline 1 constant & 17.970 & 0.928 & & 19.371 & 0.000 \\
\hline Statutory Compulsory & 0.268 & 0.123 & 0.127 & 2.172 & 0.300 \\
\hline
\end{tabular}

Multiple R -0.537, Multiple $R^{2}-0.289$, Adjusted $R^{2}=0.273$, F $3.22918-1.537-p>0.05$ 


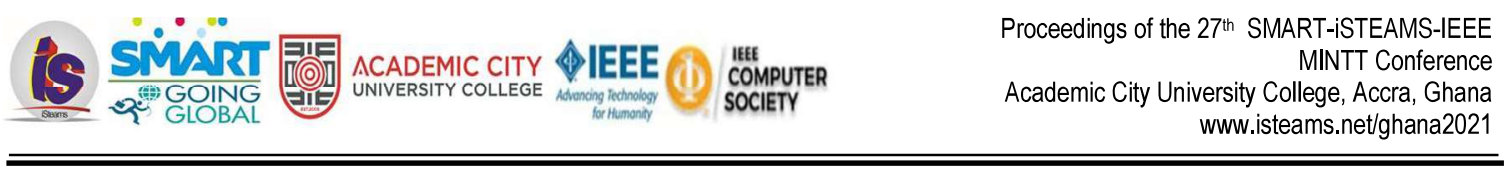

The results in table 3 above, shows that lack of non-compulsion of micro-insurance schemes amongst the teachers in the public secondary schools have a significant influence on the acceptability of micro-insurance schemes among teachers in the public secondary schools ( $F 3.22918-1.537, p>0.05)$. the null hypothesis is therefore rejected. The table reveals that the relationship between the acceptability of micro-insurance schemes and the statutory compulsion is very high, positive and statistically significant at 0.05 level ( $\beta-0.268, p>0.05)$. This implies that the lack of statutory compulsion of micro-insurance schemes have significant influence on the acceptability of micro-insurance schemes amongst the teachers and vice versa. That is the acceptability of micro-insurance scheme is influence by the statutory compulsion of the scheme. The value of the coefficient determination $\left(R^{2}-0.289\right)$ indicates that the predictor variable explained more than $1 \%\left(R^{2} \times 100\right)$ of the observed variance in the acceptability of micro-insurance amongst teachers in the public secondary schools in Lagos. The calculated F-ratio (3.22918) is significant at 0.05 level of significance. This implies that the predictor variable does provide a significant explanation for the variation in the acceptability of micro-insurance products amongst the teachers in the public secondary schools.

\section{DISCUSSION OF FINDINGS}

\section{Adequacy of Knowledge}

The result of the study shows that majority of the teachers in the public secondary school in Lagos state, have reasonable knowledge of Micro-Insurance scheme. (Allen \& Santomero, 2001; Freixas \& Rochet, 1997) opined that the search for information and options evaluation are essential ingredient needed in the purchasing decision making of a potential buyer of insurance services. However, from the study, it was observed that this does not have a positive and significant influence on the acceptability of the scheme amongst the teachers.

\subsection{Design of Micro-Insurance Products}

Micro-Insurance products designs not only look at which types of insurance products people prefers ut also how these preferences are shaped (schellhorm 2001). The information collected from the study shows that micro-insurance products in the Nigeria insurance market are well designed to influence the acceptability and purchase of micro-insurance products among the teachers in the public secondary schools in Lagos. However, the study shows that products design does not influence the acceptability and purchase of the micro-insurance products.

\subsection{Statutory Compulsion}

The acceptability of the occupational group life scheme among the employers of labour in Nigeria, according to Isimoya I. O (2012) was majorly due to the statutory compulsion of the scheme. from the research study, teachers in the public secondary schools of Lagos state have low acceptability of micro-insurance schemes, basically due to lack of statutory compulsion by the government.

\section{CONCLUSION AND COMMENTS}

\subsection{Adequacy of Knowledge}

From the data collected for the study, $80 \%$ of the respondents have a good knowledge of micro-insurance schemes. This however, does not influence the acceptability and purchase of the products among the teachers in the public secondary schools. Thus, having as low as $10 \%$ of the respondents having one form of microinsurance products. The study therefore, concludes that knowledge of teachers of the public secondary schools in Lagos state, only cannot influence the acceptability of micro-insurance 


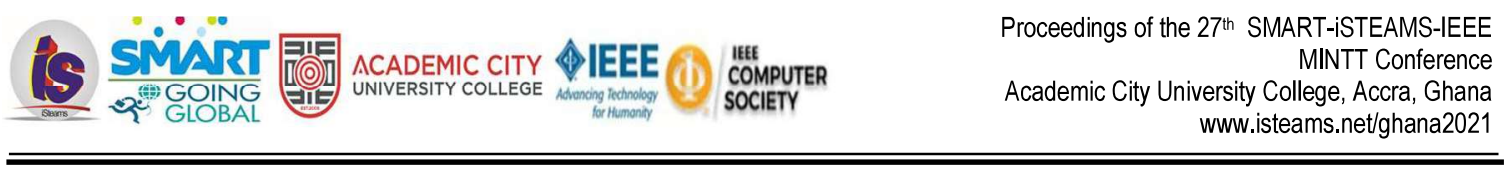

\subsection{Design of Micro-Insurance Products}

The research study also reveals that, $82 \%$ of the respondents agreed that the micro-insurance products in the market are very well designed to meet up with the financial consequences of the various risk the teachers are exposed to. This however, does not improve the acceptability and purchase of micro-insurance products among the teachers of the public secondary schools in Lagos as only about $10 \%$ of the respondents have the insurance product.

\subsection{Statutory compulsion}

$78 \%$ of the respondent's belief that there will be high acceptability from the teachers if there is a form of compelling from the government. it was reveal from the study, that most of the teachers are finding it difficult to part with some little some of money from their meagre salary for the purchase of micro-insurance products.

\section{REFERENCES}

1. Cohen, Monique, seestad, Jennifer, 1999. Can micro-insurance reduce the vulnerability of clients and their household? Prepaid for the world bank summer research workshop. Poverty and development, Washington, d. C, July 6-8

2. NAICOM ANNUAL REPORTS,2013

3. Churchill, Craig (2006)., Ed, protecting the poor: A micro -insurance compendium, ILO

4. Townsend, Robert (1994) "risk and insurance in village India. "Econometrical 62, may, 539 -592

5. Munich $\operatorname{Re}(2008)$, making insurance work for the poor., report om the micro-insurance conference 2007, published in 2008 htttp://www.munichre-foudatiom.org/stiftumgs website publication/mic2007 report_pulicatiom_summary.htm.

6. Morduch, Jonathan (2004) "consumption smoothing across space" in Stephan dercom, ed, insurance against poverty, oxford university press. 